\title{
ENHIDE telehealth support for 148 disengaged young adults with type 1 diabetes: a pilot study - rationale and study design
}

\author{
PETER H WINOCOUR, ANDREW SOLOMON, ANNE CURRIE, DAWN HARDY, KAREN MOORE-HAINES, \\ CLAIRE RENSHAW
}

\begin{abstract}
Disengaged young adults with type 1 diabetes are vulnerable to poor health outcomes. Potentially $20 \%$ of those aged 16-30 years could be included in this category. East and North Herts Clinical Commissioning Group (CCG) commissioned the East and North Herts Institute of Diabetes and Endocrinology (ENHIDE) to pilot an innovative model of care in August 2016. Young adults aged 16-30 were offered an alternative model of tailored care, with access to a young adult support worker and specialist nurse. Inclusion in the project was based on fulfilling at least one of the following criteria:

- Acute admission with diabetic ketoacidosis or hypoglycaemia

- Non-attendance for retinal screening

- Non-attendance at clinics on at least two consecutive occasions

- Persistent $\mathrm{HbA}_{1 \mathrm{c}}$ levels $>75 \mathrm{mmol} / \mathrm{mol}$

- Non-attendance for routine laboratory measures of glycaemia and renal function

- Multidisciplinary team review stating need for more flexible care

We invited 148 young adults to participate in the project. Of these, 118 have been recruited after the initial contact, markedly exceeding the $10 \%$ take-up rate set by the CCG. The project will evaluate changes in emergency admissions, attendance for routine biochemical tests and retinal screening, changes in glycaemic control and quality of life measures at 6 and 12 months after entry to the project Br J Diabetes 2018:18:154-162
\end{abstract}

Key words: young adults, type 1 diabetes, telehealth, disengaged

ENHIDE (East and North Herts Institute of Diabetes and Endocrinology), Howlands Clinic, QEll Hospital, Welwyn Garden City, Herts AL7 4HQ, UK

Address for correspondence: Dr Peter $\mathrm{H}$ Winocour ENHIDE (East and North Herts Institute of Diabetes and Endocrinology), Howlands Clinic, QEIl Hospital, Welwyn Garden City, Herts AL7 4HQ, UK E-mail: peter.winocour@nhs.net

https://doi.org/10.15277/bjd.2018.191

\section{Background}

Clinical management and self-care of young adults with type 1 diabetes is challenging. There is an evident need for effective transitional care of those aged 16-19 years, but also recognition of issues with transfer of care to adult services. ${ }^{1-3}$ There are more adults aged 19-30 with type 1 diabetes - including those who have developed their condition after the age of paediatric care - than those aged 16-19.

Several studies have clearly demonstrated the multifaceted nature of issues that impact on attendance at clinics for young adults, adherence to self-care, hospitalisation with diabetic ketoacidosis (DKA), high levels of $\mathrm{HbA}_{1 \mathrm{c}}$ and early onset complications, most notably retinopathy. These include psychosocial factors such as socioeconomic status, parental separation and lack of family cohesiveness, unemployment, and psychological and mental health factors including eating disorders and substance abuse. ${ }^{4,5}$ In addition, there is clear evidence that a proportion of young adults living with type 1 diabetes do not find current models of care provide services they wish to access. ${ }^{6}$

Less engaged patients have poor glycaemic control, the highest rates of DKA admissions and non-attendance at clinics, and the greatest incidence of complications. ${ }^{7,8}$ Certain models using nondirect face-to-face communication using Skype and text-based support have provided benefits such as better clinical attendance and potentially fewer emergency admissions..$^{9-13}$ These services have been offered to all patients attending diabetes clinics rather than selected patients with poor clinic attendance. ${ }^{9}$

Despite recent advances in diabetes care and more intensified insulin regimens, much higher levels of $\mathrm{HbA}_{1 c}$ than are desirable persist. ${ }^{14-16}$ Furthermore, psychological interventions designed to help young people with type 1 diabetes have achieved disappointing results in respect of engagement, $\mathrm{HbA}_{1 \mathrm{c}}$ attainment and improved quality of life measures. ${ }^{17}$

By definition, it might be difficult to identify factors that account for dissatisfaction with standard care. However, this has recently been explored in a semi-structured interview with 29 young people with type 1 diabetes ${ }^{6}$ who fulfilled any of the following criteria: no $\mathrm{HbA}_{1 \mathrm{c}}$ test in preceding 12 months, non-attendance for retinal screening in the preceding 18 months, no contact with the specialist diabetes team for 12 months, or two or more hospital admissions with DKA in the past 2 years. 
The themes that emerged were:

- Feeling overwhelmed by having and managing type 1 diabetes

- Experience of bereavement

- Feeling different to peers without type 1 diabetes

- Trust previously broken by a health professional

- Embarrassment at discussing menstruation, personal issues and being examined by male doctors

- Length of time and inconvenience attending clinic appointments

- Concern they were being 'blamed' for ineffective self-management

In East and North Hertfordshire there are approximately 800 people with type 1 diabetes aged 16-30. Surveys of our transition and young adult clinics in 2014 recorded a 23\% drop-out rate after 2 years follow-up. ${ }^{18}$ In 2016 there were 52 young adults aged 16-30 with at least one DKA admission over an 18-month period identified from Hospital Episode Statistics. The last recorded median value of $\mathrm{HbA}_{1 \mathrm{c}}$ available in 49 cases was $93 \mathrm{mmol} / \mathrm{mol}$. Eighteen of these were disengaged from regular care. Our DKA admission rates equate to a $4.3 \%$ annual event frequency, in line with UK and international reports, with the highest incidence being amongst those aged $18-24.8,19,20$

The East and North Herts Diabetes Retinal Screening programme in 2016 identified 66 young adults aged 16-30 who had not attended retinal screening. This is a serious concern, given the link with variable engagement and the recognition that the incidence of sight-threatening retinal disease and blindness is especially high below the age of $40.14,15$

\section{The ENHIDE Young Adult Telehealth Pilot Study}

The 2-year project was designed to enable at least 12 months review of the impact of supported care on the outcome measures. The East and North Herts Clinical Commissioning Group (CCG) provided financial support for the core personnel and for IT support. The project was set up in August 2016, with full recruitment of the team by the end of October 2016.

\section{Outline of patient selection}

The project was designed to provide an alternative care model for those identified as 'disengaged'. This categorisation is not a binary definition in that young adults with diabetes can engage with certain aspects of routine care on an intermittent basis.

Consequently, inclusion in the telehealth service for individuals aged 16-30 was based on meeting at least one of the following criteria in the 2 years prior to project entry:

- Admission with diabetic ketoacidosis or hypoglycaemia

- Non-attendance for retinal screening

- Non-attendance at diabetes clinics on at least two consecutive occasions

- Persistent $\mathrm{HbA}$ ic levels $>75 \mathrm{mmol} / \mathrm{mol}$

- Non-attendance for routine laboratory measures of glycaemia and renal function

- Multidisciplinary team review stating the need for a more flexible system of supported care.

Young adults aged 16-30 years in East and North Herts were identified from outpatient and inpatient hospital registers, the Diabetes
Retinal Screening register and individual patients identified from GP practice registers. All 55 general practices in East and North Herts were invited to participate. GP practices were informed about the project via a GP bulletin. The CCG made practices aware of the project time scales, aims and objectives and offered a financial incentive ( $\mathrm{f200}$ ) for participation.

Young adults aged 16-30 admitted with DKA and/or hypoglycaemia were prioritised for immediate entry along with potential disengaged cases from specialist diabetes services. All general practices were contacted to create a cross-referenced list enabling updates of those currently registered at the practice with type 1 diabetes aged 16-30. This enabled documentation on whether individuals had changed practices, or had been admitted to other acute units within the preceding 2 years, and helped identify lack of key biomedical data within the preceding 2 years. We also identified additional psychosocial, employment information and other issues.

Young adults who no longer lived in the East and North Herts catchment area were excluded from consideration to participate in the study.

\section{The telehealth team}

The telehealth project team comprised two consultant diabetologists who provided a total of two sessions weekly for this project, two Band 7 diabetes specialist nurses (DSNs) who provided a total of five full days a week, a half-time project manager and a whole-time young adult support worker (YASW).

\section{Development of the young adult telehealth protocol}

The telehealth team initially identified three pilot practices from three separate localities in East and North Herts. A detailed baseline proforma (Figure 1), which included an individualised care plan, was completed and agreed by the telehealth team. All young adults identified for the project were invited to participate by letter (Figure 2) which was tailored to their individual needs. Those still under transitional care were invited to participate by the paediatric department.

We trialled methods of delivering the invitation: attached alongside the repeat insulin prescription, hand delivered to home addresses or via the Practice Nurse. The young adult was given 5 days to 'opt out' of the project before the team made contact.

We asked primary care and young adults from the three 'pilot' practices for suggested changes to this process. Subsequently we hand delivered invitations to the home addresses. This gave the team the opportunity to speak to the young adults in person if they were at home, and the process was repeated 8-12 weeks later if no contact had been achieved.

\section{Ongoing project delivery}

After initial contact, participants were asked to complete a 'Problem Areas in Diabetes' (PAID) Questionnaire used in the DAWN study ${ }^{21}$ and eight questions from The Diabetes Wellbeing Questionnaire used by the National Paediatric Diabetes Network (Figure 3).

Day-to-day support was provided by the DSNs and the YASW. After initial input, the consultant role remained supervisory, other 
Figure 1. Proforma for baseline data collection

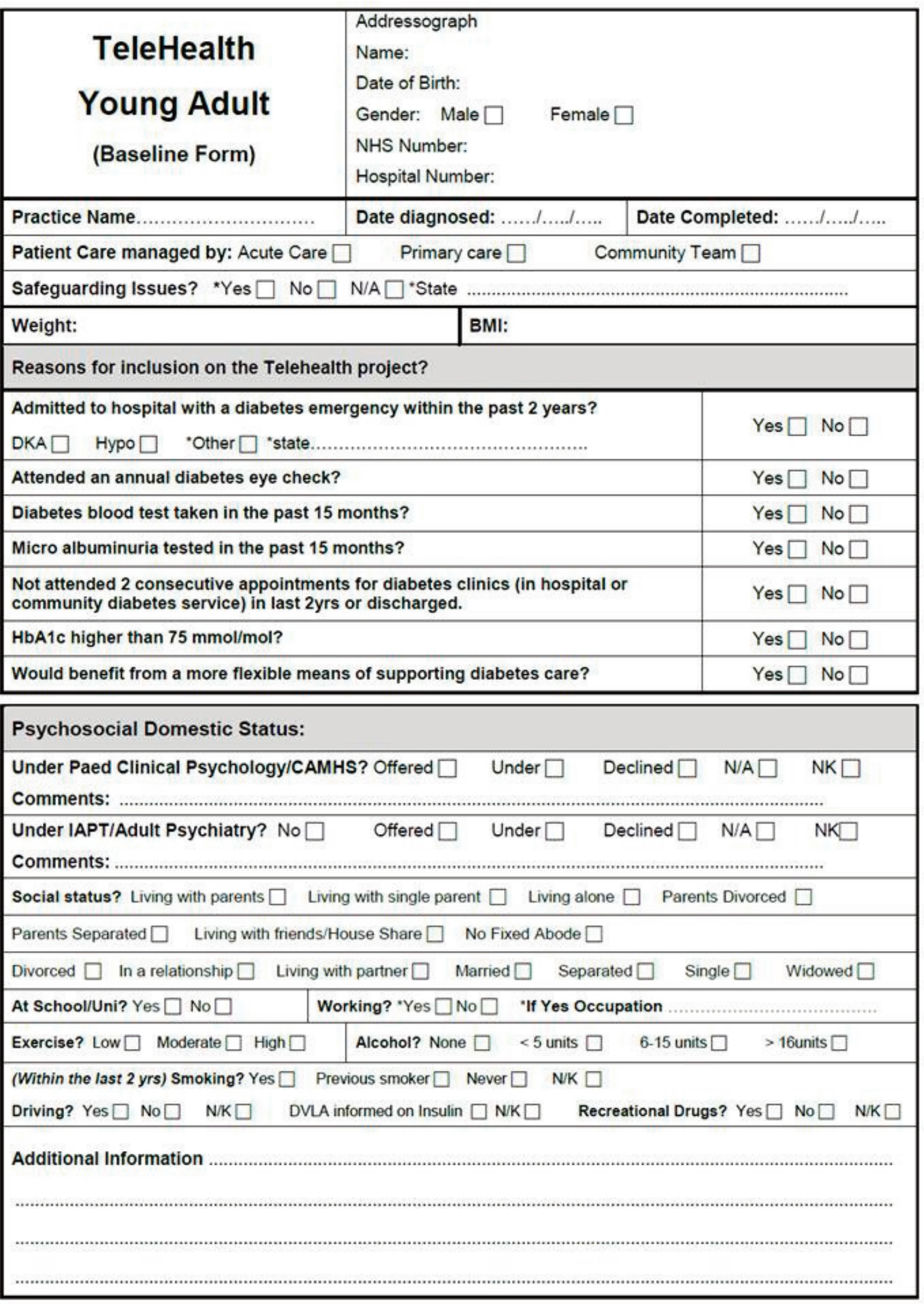


Figure 1. Proforma for baseline data collection (continued)

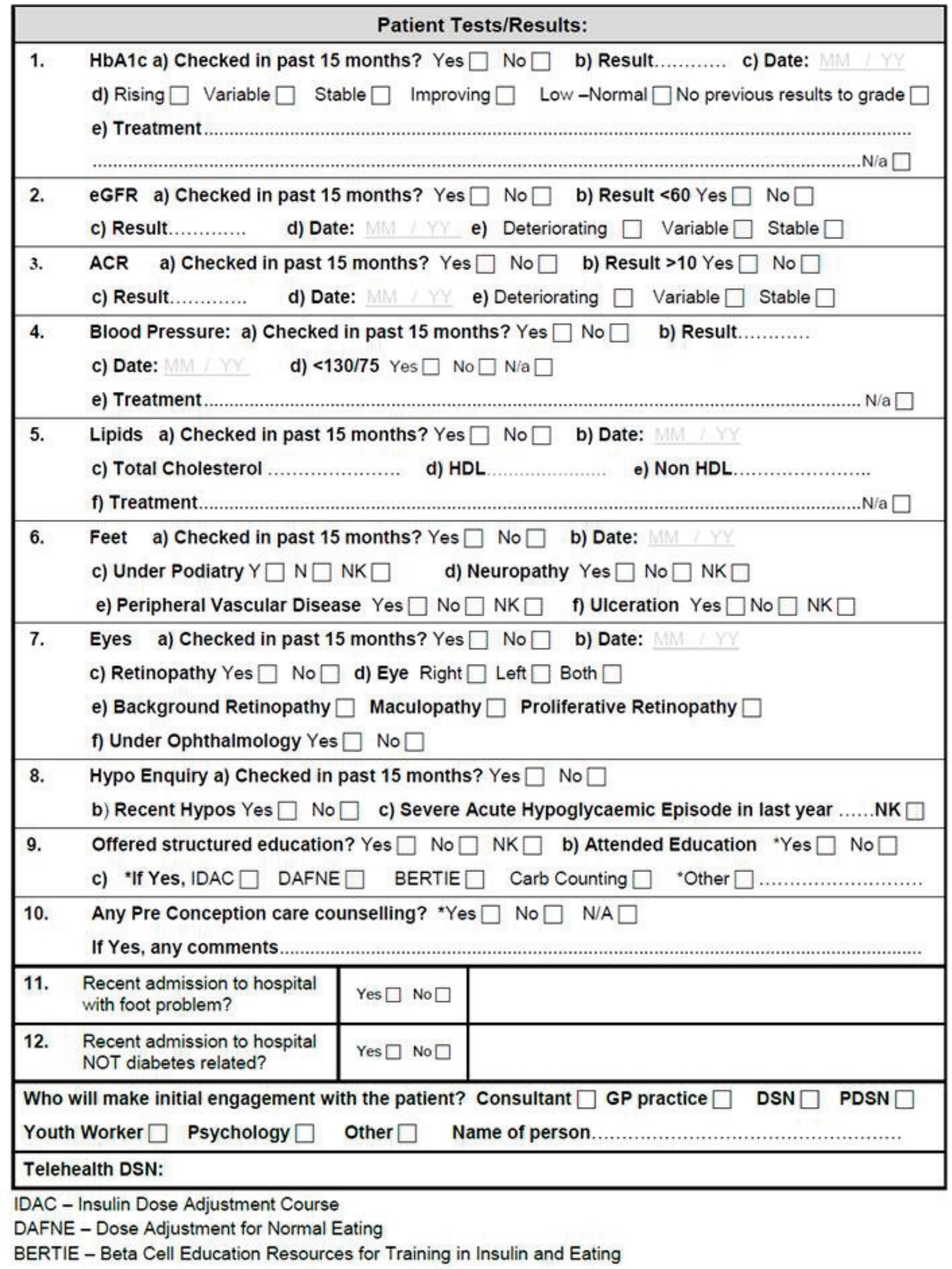


Figure 1. Proforma for baseline data collection (continued)

\begin{tabular}{|l|c|}
\hline 'Problem Areas in Diabetes' questionnaire completed? & Yes $\square$ No $\square$ \\
\hline 'Wellbeing in Diabetes' questionnaire completed? & Yes $\square$ No $\square$ \\
\hline
\end{tabular}

Young adult agreed priorities

Criteria to demonstrate improvement

$\square$ Avoidance of hospital admissions

$\square$ Improve mental well being

$\square$ Obtain $\mathrm{HbA} 1 \mathrm{c}<75 \mathrm{mmol} / \mathrm{mol}$

$\square$ Attend annual diabetes eye check

$\square$ Have bloods taken

$\square$ Have micro albuminuria taken

$\square$ Improve engagement with HCP via clinics/telehealth

Other information 
Figure 2. Invitation to participate
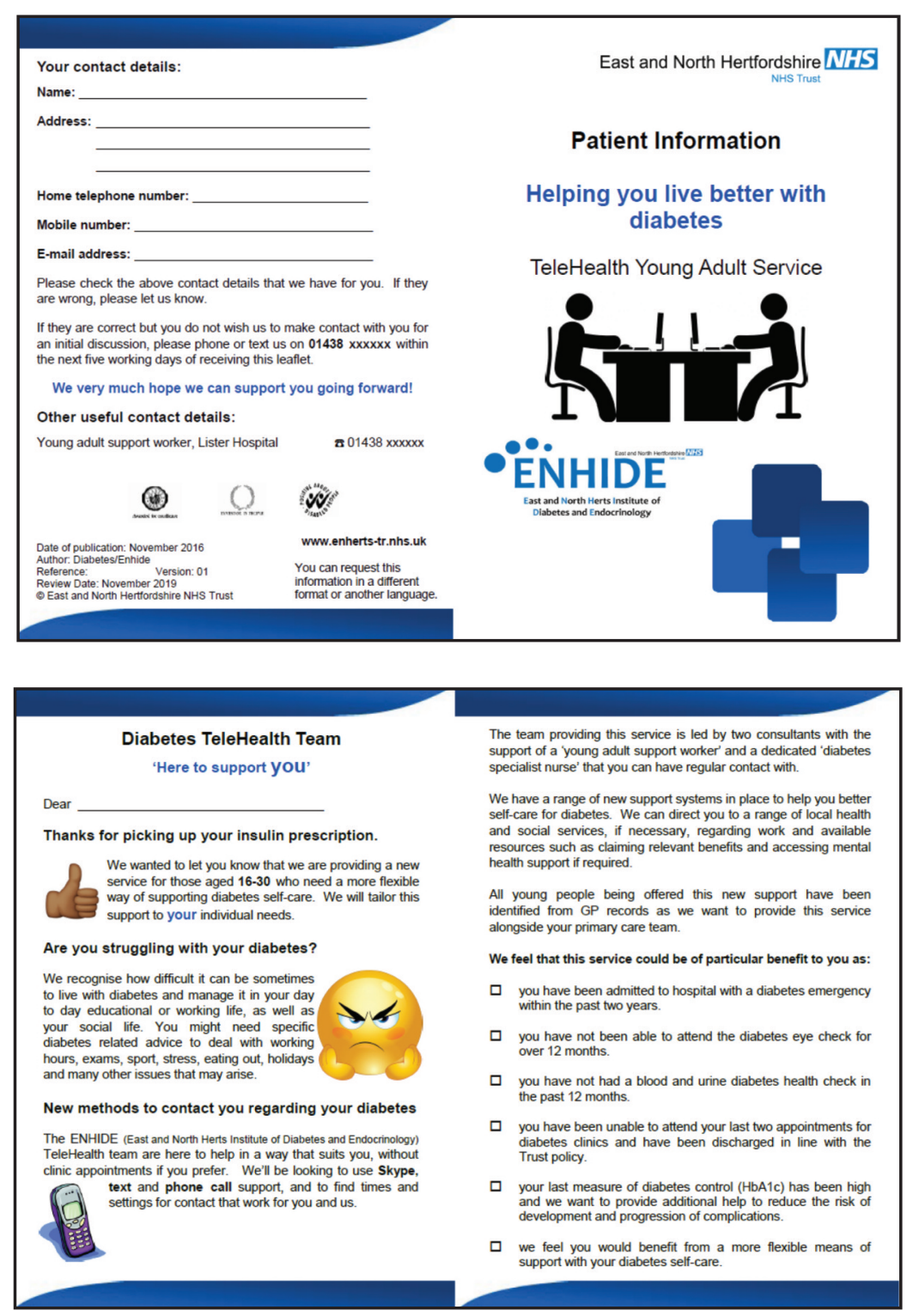

than review of cases admitted with ketoacidosis or hypoglycaemia. Consultant reviews were offered at patients' request. In addition to the goals the patient wished to achieve by being part of the project, an individual care plan was also agreed by the team.

The key role for the YASW was to help participants navigate around medical, social and employment services, to ensure access for support for low-grade mood disorders provided by Hertfordshire County Council and national services such as the 'Big White Wall' and Samaritans, and to improve access to cognitive behavioural therapy. Individuals requiring behavioural support were identified based on responses to the PAID or Wellbeing questionnaires. Services were accessed by selfreferral or via the project team. In addition, the YASW provided moral support and basic diabetes advice, and access to smoking cessation programmes (Table 1).

The YASW and the DSNs had discussion with the mental health team to ensure access to clinical psychology and/or psychiatric care for complex mental health issues.
We collaborated with the retinal screening team to offer more flexible screening times at weekends and evenings, offering DSN review to coincide with the time of eye screening.

The DSNs and YASW used text, telephone and Skype communication with young adults who requested such support. The timings for access were mutually agreed, enabling contacts at weekend and outside working hours.

Clinical support from the DSNs enabled conversion to peakless basal insulin such as Degludec, use of meters with apps, and readier access to downloading blood glucose readings using DIASEND. A subgroup of individuals with recurrent DKA and/or no record of blood glucose monitoring were selected by the DSNs to have FreeStyle Libre Flash glucose monitoring for a minimum of 1 month to better support self-care, recognition of glycaemia, and need for more effective use of insulin to match carbohydrate intake. This enabled the DSNs to support changes to insulin regimens where nocturnal hypoglycaemic events were documented, or enable carbohydrate counting with insulin bolus advisors.

Use of smart phone applications such as 'Carbs and Cals' was encouraged. Dietetic support was offered through a 3-hour carbohydrate counting course or through more structured education.

All data and contacts were captured on our diabetes data management system after initial baseline documentation was captured using a standardised proforma (Figure 1). Hospital admissions of those included in the study were identified through the Diabetes Outreach Team.

Monthly case reviews by the project team were established to assess adherence to the programme. Quarterly $\mathrm{HbA}_{1 c}$ measurements were arranged if individual patients were agreeable. Information on the clinical impact and engagement of the patient throughout the project lifecycle was recorded at 6 and 12 months after inception, enabling direct comparison with baseline data to monitor project success.

The original CCG support was contingent on attainment of the key performance indicators in those recruited in this pilot study. These included:

- The proportion of the young adults taking up the offer of support: a minimum of $10 \%$ set as a goal

- Baseline and post service changes in individualised care plan improvements

- Ambulance call-outs for young adults with hypoglycaemia reduced by $20 \%$

- Reduction in DKA admissions by $20 \%$ 
Figure 3. Young Adult Wellbeing Patient Questionnaire

Patient Name:

Completion Date:

Interview Date:

\begin{tabular}{|c|c|c|c|c|c|}
\hline & $\begin{array}{c}\text { Not a } \\
\text { problem }\end{array}$ & $\begin{array}{c}\text { Minor } \\
\text { Problem }\end{array}$ & $\begin{array}{l}\text { Moderate } \\
\text { Problem }\end{array}$ & $\begin{array}{l}\text { Somewhat } \\
\text { serious } \\
\text { Problem }\end{array}$ & $\begin{array}{l}\text { Serious } \\
\text { Problem }\end{array}$ \\
\hline 1. Not having clear and concrete goals for your diabetes care? & 0 & 1 & 2 & 3 & 4 \\
\hline 2. Feeling discouraged with your diabetes treatment plan? & 0 & 1 & 2 & 3 & 4 \\
\hline 3. Feeling scared when you think about living with diabetes? & 0 & 1 & 2 & 3 & 4 \\
\hline $\begin{array}{l}\text { 4. Uncomfortable social situations related to your diabetes care } \\
\text { (e.g., people telling you what to eat)? }\end{array}$ & 0 & 1 & 2 & 3 & 4 \\
\hline 5. Feelings of deprivation regarding food and meals? & 0 & 1 & 2 & 3 & 4 \\
\hline 6. Feeling depressed when you think about living with diabetes? & 0 & 1 & 2 & 3 & 4 \\
\hline $\begin{array}{l}\text { 7. Not knowing if your mood or feelings are related to your } \\
\text { diabetes? }\end{array}$ & 0 & 1 & 2 & 3 & 4 \\
\hline 8. Feeling overwhelmed by your diabetes? & 0 & 1 & 2 & 3 & 4 \\
\hline 9. Worrying about low blood sugar reactions? & 0 & 1 & 2 & 3 & 4 \\
\hline 10. Feeling angry when you think about living with diabetes? & 0 & 1 & 2 & 3 & 4 \\
\hline 11. Feeling constantly concerned about food and eating? & 0 & 1 & 2 & 3 & 4 \\
\hline $\begin{array}{l}\text { 12. Worrying about the future and the possibility of serious } \\
\text { complications? }\end{array}$ & 0 & 1 & 2 & 3 & 4 \\
\hline $\begin{array}{l}\text { 13. Feelings of guilt or anxiety when you get off track with your } \\
\text { diabetes management? }\end{array}$ & 0 & 1 & 2 & 3 & 4 \\
\hline 14. Not "accepting" your diabetes? & 0 & 1 & 2 & 3 & 4 \\
\hline 15. Feeling unsatisfied with your diabetes physician? & 0 & 1 & 2 & 3 & 4 \\
\hline $\begin{array}{l}\text { 16. Feeling that diabetes is taking up too much of your mental } \\
\text { and physical energy every day? }\end{array}$ & 0 & 1 & 2 & 3 & 4 \\
\hline 17. Feeling alone with your diabetes? & 0 & 1 & 2 & 3 & 4 \\
\hline $\begin{array}{l}\text { 18. Feeling that your friends and family are not supportive of your } \\
\text { diabetes management efforts? }\end{array}$ & 0 & 1 & 2 & 3 & 4 \\
\hline 19. Coping with complications of diabetes? & 0 & 1 & 2 & 3 & 4 \\
\hline $\begin{array}{l}\text { 20. Feeling "burned out" by the constant effort needed to } \\
\text { manage diabetes? }\end{array}$ & 0 & 1 & 2 & 3 & 4 \\
\hline $\begin{array}{l}\text { 21. There have been changes in my usual eating patterns or } \\
\text { appetite }\end{array}$ & 0 & 1 & 2 & 3 & 4 \\
\hline 22. I have been feeling more sad / lower in mood than usual & 0 & 1 & 2 & 3 & 4 \\
\hline 23. I have been worrying or feeling nervous more than usual & 0 & 1 & 2 & 3 & 4 \\
\hline 24. I have found things at home more difficult than usual & 0 & 1 & 2 & 3 & 4 \\
\hline $\begin{array}{l}\text { 25. I have found doing school / college work more difficult than } \\
\text { usual }\end{array}$ & 0 & 1 & 2 & 3 & 4 \\
\hline $\begin{array}{l}\text { 26. I have found getting on with friends / other pupils / students } \\
\text { more difficult than usual }\end{array}$ & 0 & 1 & 2 & 3 & 4 \\
\hline $\begin{array}{l}\text { 27. I have found doing what is needed to look after the diabetes } \\
\text { more difficult than usual e.g. injections, blood tests, carb } \\
\text { counts etc }\end{array}$ & 0 & 1 & 2 & 3 & 4 \\
\hline 28. I am worried about how we are coping as a family & 0 & 1 & 2 & 3 & 4 \\
\hline
\end{tabular}


Table 1 Local and national support services signposted by young adult support worker

Local services

FRANK Adolescent Drugs and Alcohol Service Herts (online drugs advice)

Mind in Mid Herts (mental health support)

IFST (Intensive Family Support Team)

Youth Connexions (mental health, sexual health, education and employment support)

YMCA (support with health and wellbeing, homelessness, family support, training, education and youth work)

The Wellbeing Service Herts (mental health support)

Rapid Assessment Interface and Discharge (RAID) (mental health in patient liaison service)

$\mathrm{LGBT}^{\star} \mathrm{Q}$ in Hertfordshire (lesbian, gay, bisexual, trans and questioning support, advice and events)

A-Dash (Adolescent \& Alcohol Service Herts)

Sexual health clinics

Herts Young \& Homeless

Herts CAMHS (Child Adolescent Mental Health Service)

Dyslexia Herts

Herts Help (range of different support)

Smoke Free Hertfordshire

Herts Sunflower (Herts domestic abuse helpline)
National services

Diabetes UK

JDRF (online type 1 diabetes support)

Carbs and Cals (online, books and APPS)

Young Minds (child and adolescent mental health support)

Self-harm UK (online support)

Kooth (children, adolescent online counselling support)

Samaritans (Helpline)

Beat (beating eating disorders)

Brook (eating disorder support

British Dyslexia Association (online support)

Change 4 Life (exercise \& diet)

Rethink Mental Health (online support)

Sane (mental health helpline)

PALMS (positive behaviour, autism, learning disability and mental health)

The Big White Wall (online counselling)
- Improved quality of life measures

- Feedback on patient experience

The project did not commence without challenges:

- Only $70 \%$ of the 55 practices expressed interest in supporting the project and providing additional information on patients who met the project criteria; the response was lower from those practices on the fringes of the CCG catchment area.

- Contact details in acute and primary care information systems were not always up to date, raising concern that those considered disengaged may not have received regular communication both prior to and during the initial phase of the pilot study. This became apparent in approximately $40 \%$ of cases when a successful second home visit with direct contact identified changes in mobile phone numbers.

- Absence of blood testing often reflected lack of willingness to wait in lengthy queues in the pathology department.

- Face-to-face contact was limited to certain locations on grounds of safety and data protection.

\section{Current status}

Initially the project anticipated there would be 200 eligible young adults from the start of recruitment in October 2016. At completion of recruitment in September 2017, 148 young adults not under acute care elsewhere fulfilled criteria for participation.

The majority $(n=120)$ were on basal bolus insulin regimens, 23 were on 1-3 daily injections using pre-mixed and rapid acting

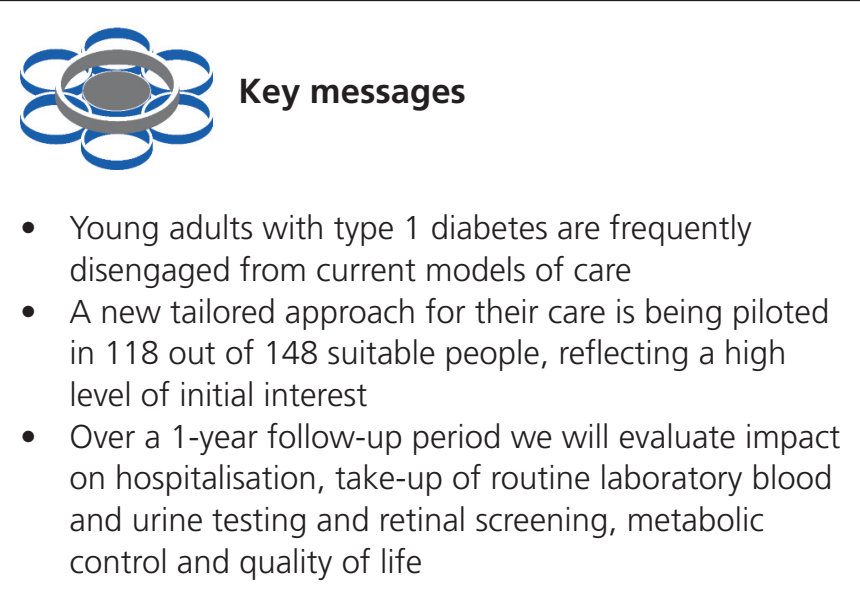

insulin and five were on insulin pumps. Overall, 80\% $(n=118)$ responded to the invitation to participate in the project, which was staggered over the period from October 2016 to September 2017. Data capture at 6 and 12 months after initiation will enable review of the project outcomes towards the end of 2018.

The ENHIDE young adult telehealth pilot project was designed as a collaborative exercise between primary and specialist care. We have demonstrated in the establishment of the programme that this is both feasible and necessary. If successful, the economic cost per case supported (less than $£ 1000$ annually covering the salary costs of the 
telehealth team) would be measured against the short-term benefits from reduced unscheduled hospital admissions and better use of clinic appointments, and the potential longer-term savings through reduced diabetes complications.

\section{Conflict of interest: None}

Funding: This project was funded by The East and North Herts Clinical Commissioning Group with additional support from an unrestricted medical educational grant from Sanofi Aventis towards DSN salary costs.

\section{References}

1. Winocour PH. Care of adolescents and young adults with diabetes much more than transitional care. A personal view. Clin Med 2014;14 274-8. https://doi.org/10.7861/clinmedicine.14-3-274

2. Allen $D$, Cohen $D$, Hood $K$, et al. Continuity of care in the transition from child to adult diabetes services: a realistic evaluation study. J Health Serv Res Policy 2012;17:140-8. https://doi.org/10.1258/jhsrp.2011.011044.

3. Garvey KC, Wolpert HA, Finkelstein JA. Heath care transition in young adults with type 1 diabetes. Barriers to timely establishment of adult diabetes care. Endocrine Pract 2013;189:946-52. https://doi.org/10.4158/EP13109.OR

4. Wagner DV, Stoeckel M, Tudor ME, Harris MA. Treating the most vulnerable and costly in diabetes. Curr Diab Rep 2015;15:606. https://doi.org/10.1007/s11892-015-0606-5

5. Hynes L, Byrne M, Dinneen SF, McGuire BE, O’Donnell M, McSharry J. Barriers and facilitators associated with attendance at hospital diabetes clinics among young adults (15-30 years) with type 1 diabetes mellitus: a systematic review. Pediatr Diabetes 2016;17:509-18. https://doi.org/10.1111/pedi.12198

6. Smeaton E. Bridging the gap: meeting the healthcare needs of young people with type 1 diabetes. Report for Diabetes UK, 2015.

7. Castensoe-Seidenfaden P, Jensen AK, Smedegaard H, et al. Clinical, behavioural and social indicators for poor glycaemic control around transfer to adult care: a longitudinal study of 126 young people with diabetes. Diabet Med 2017:34:667-75. https://doi.org/10.1111/dme.13318

8. Holmes Walker DJ, Llewellyn AC, Farrell K. A transition care programme which improves diabetes control and reduces hospital admission rates in young adults with type 1 diabetes aged 15-25 years. Diabet Med 2007;24:764-9. https://doi.org/10.1111/j.1464-5491.2007.02152.x

9. Vijayaraghavan $S, O^{\prime}$ Shea T, Campbell-Richards D, et al. DAWN: Diabetes appointments via webcam in Newham. Br J Diabetes Vasc Dis 2015; 15:123-6. http://dx.doi.org/10.15277/bjdvd.2015.032

10. Greenhalgh T, Vijayaraghavan S, Wherton J, et al. Virtual online consultations: advantages and limitations (VOCAL) study. BMJ Open 2016;6(1):e009388. https://doi.org/10.1136/bmjopen-2015-009388
11. Malasanos TH, Burlingame JB, Youngblade $L$, et al. Improved access to subspecialist diabetes care by telemedicine: cost savings and care measures in the first two years of the FITE diabetes project. J Telemed Telecare 2005;11(Suppl 1):74-6. https://doi.org/10.1258/1357633054461624

12. Harris MA, Freeman KA, Duke DC. Seeing is believing: using Skype to improve diabetes outcomes in youth. Diabetes Care 2015;38:1427-34. https://doi.org/10.2337/dc14-2469

13. Franklin VL, Waller A, Pagliari C, Greene SA. A randomized controlled trial of Sweet Talk, a text-messaging system to support young people with diabetes. Diabet Med 2006;23:1332-8. https://doi.org/10.1111/j.1464-5491.2006.01989.x

14. Johnson B, Elliott J, Scott A, et al. Medical and psychological outcomes for young adults with type 1 diabetes: no improvement despite recent advances in diabetes care. Diabet Med 2014;31:227-31. https://doi.org/10.1111/dme.12305

15. Carlsen S, Skrivarhaug T, Thue G, et al. Glycemic control and complications in patients with type 1 diabetes: a registry-based longitudinal study of adolescents and young adults. Pediatr Diabetes 2016;18:188-95. https://doi.org/10.1111/pedi.12372

16. Sildorf SM, Hertel NT, Thomsen J, et al, on behalf of the Danish Study Group of Diabetes in Children. Treatment intensification with improved $\mathrm{HbA} 1 \mathrm{c}$ levels in children and adolescents with type 1 diabetes mellitus. Diabet Med 2016;33:515-22. https://doi.org/10.1111/dme.12900

17. Christie D, Thompson R, Sawtell M, et al. Effectiveness of a structured educational intervention using psychological delivery methods in children and adolescents with poorly controlled type 1 diabetes: a clusterrandomized controlled trial of the CASCADE intervention. BMJ Open Diabetes Res Care 2016;4(1):e000165. https://doi.org/10.1136/bmjdrc-2015-000165

18. Winocour PH. Transition or transfer of care of young adults with diabetes: more than semantics and a challenge for adult diabetes care? Poster Presentation at 'Transition: developmentally appropriate care for young people with long term conditions'. RCP London Meeting, October 2015.

19. Maahs DM, Hermann JM, Holman N, et al. Rates of diabetic ketoacidosis: international comparison with 49,859 pediatric patients with type 1 diabetes from England, Wales, the US, Austria and Germany. Diabetes Care 2015;38:1876-82. https://doi.org/10.2337/dc15-0780

20. Zhong VW, Juhaeri J, Mayer-Davies EJ. Trends in hospital admission for diabetic ketoacidosis in adults with type 1 and type 2 diabetes in England, 1998-2013: a retrospective cohort study. Diabetes Care 2018; 41:1870-7. https://doi.org/10.2337/dc17-1583

21. Peyrot $M$, Rubin RR, Lauritzen $T$, et al, on behalf of the International DAWN Advisory Panel. Psychosocial problems and barriers to improved diabetes management: results of the Cross-National Diabetes Attitudes, Wishes and Needs (DAWN) study. Diabet Med 2005;22:1379-85. https://doi.org/10.1111/j.1464-5491.2005.01644.x

\section{Diary dates 2019}

6 February $\quad A B C D$ Yorkshire Regional Diabetes Event

York Racecourse

https://abcd.care/events/abcd-yorkshire-regional-diabetes-event

13 February 4th Joint Meeting of $A B C D$ and the Renal Association NEC, Birmingham

https://abcd.care/events/4th-joint-meeting-abcd-renal-association

\section{February Obesity Update 2019}

Royal College of Physicians, London

https://www.bioscientifica.com/event-management/ourevents/obesity-update-2019/
16 May

ABCD DTN-UK Meeting 2019

Loughborough University

https://abcd.care/events/abcd-dtn-uk-meeting-2019

\section{6/17 May ABCD Spring Meeting}

Loughborough University

https://abcd.care/events/abcd-spring-meeting-2019

For other meetings see https://www.abcd.care/events 